\title{
NECESIDADES, DERECHOS Y METODOLOGÍA DE APERTURA
}

\section{NECESSIDADES, DIREITOS E METODOLOGIA DE ABERTURA}

\section{NECESSITIES, RIGHTS AND OPENING METHODOLOGY}

\begin{abstract}
RODRIgo CALDERÓN ASTETE
Maestro en Teorías Críticas del Derecho Universidad Internacional de Andalucía, España. Doctor en Derecho, Universidad Pablo de Olavide, Sevilla España. Post Doctor en Programa de Post graduación en Políticas Sociales, Universidad Católica de Pelotas. RS. Brasil. Profesor de Derechos Humanos, Teoría del Derecho y Derecho laboral, Universidad Academia de Humanismo Cristiano, Chile.. (Concepción, Chile) rodrigocalderonster@gmail.com
\end{abstract}

\begin{abstract}
RESUMEN
La modernidad se ha conformado, en tanto paradigma, sobre una matriz de ciencia matematizante, tendiente a la abstracción y a la separación sujeto-objeto. De allí se ha derivado a su vez un método de conocimiento que separa saber de hacer, que se centra en el individuo atomizado y establece pasos ritualizados para una verdad única. Esto impacta en la forma de abordar la satisfacción de las necesidades humanas, los derechos de los sujetos y sus formas de relacionamiento. Para enfrentar estas dificultades proponemos trabajar una metodología de apertura, dinámica, de la potencia, materialista y finalista.
\end{abstract}

Palabras claves: Paradigma; Necesidades, Derechos, Apertura, Pluralidad.

\section{RESUMO}

A modernidade é formada, enquanto paradigma em uma matriz de ciência matematizadora, tende à abstração e separação sujeito-objeto, que, pro sua vez, foi derivado de um método de conhecimento que separa saber de fazer, que incide sobre o indivíduo atomizado e define passos ritualizados para uma única verdade. Isso afeta a forma de abordar a satisfação das necessidades humanas, direitos das pessoas e formas de relacionamento. Para responder a estas dificuldades, propõe-se a trabalhar uma metodologia de abertura, dinâmica, poder, materialista e finalista.

Palavras-chave: Paradigmas; Necessidades; Direitos; Abertura; Pluralidade.

\section{ABSTRACT}

Modernity has become, as a paradigm, a matrix of mathematical science, tending to abstraction and subject-object separation. From there has itself derived a method of knowledge that separates knowing from doing, which focuses on the atomized individual and establishes ritualized steps for a single truth. This impacts on the way to address the satisfaction of human needs, the rights of the subjects and their forms of relationship. In order to face these difficulties we propose to work a methodology of openness, dynamic, of the power, materialist and finalist.

Keywords: Paradigm; Necessities; Rights; Openness; Plurality.

\section{SUMÁRIO}

INTRODUCCIÓN; 1 CIENCIA, MÉTODO, REFLEXIÓN-ACCIÓN. 2 EMANCIPACION Y NUEVOS PARADIGMAS. 2.1. Hacer visible lo real. 2.2 Cambiar la mirada. 2.3 Pensar de outro modo. 3.4 Cambiar de emocionalidad. 2.5 Modificar las interaciones. CONCLUSÍON. REFERENCIAS. 


\section{INTRODUCCIÓN}

La repetición de las fórmulas y las actividades conspiran contra la eficacia en la lucha por los derechos, la satisfacción de las necesidades y la dignidad humana. Nuestro hacer, nuestros objetivos, logros y memoria se vuelven inconstantes, distantes, opacos en esa reiteración prevista. Y esto es más que un problema gnoseológico.

En La Gaya Ciencia Nietzsche escribía: "Se considera que la necesidad es la causa de lo que se forma, cuando verdaderamente a menudo no es más que el efecto de lo que se ha formado"1; instalando en el problema del conocimiento una perspectiva que contradice el criterio de la ciencia moderna, invirtiendo el sentido de la actividad pensar/hacer contra la naturalización de conceptos previos colocados como premisas por un acto de poder que los instala.

Acostumbrados a transitar en el paradigma en que hemos sido formados, lleno de conceptos abstractos, prejuicios, nociones y sentidos propios, enredados en las discusiones acerca de la denominación de los fenómenos, que pierden así su ethos original y se re-significan, la confusión se expande, la discusión se concentra en la validez de nuestras respuestas fragmentadas frente a la realidad. El discurso que insiste en la receta técnica choca con los resultados de esas aplicaciones. ¿Cómo dar cuenta de la realidad y su complejidad? ¿Usar metáforas en vez de certezas apodícticas y catalogables de científicas exactas, no solo para explicarnos el mundo, sino para cambiarlo? El arsenal de pensamiento de que disponemos parece sobrepasado, agotado. ¿Pero cómo pensar de otro modo, cómo encontrar o construir respuestas, alternativas, opciones al sistema mundo que se nos impone?

Pensar de otro modo requiere ser capaces de salir de la trampa de la uniformidad y del orden absoluto, del método único, del conocimiento centrado en una verdad revelada o encontrada, trabajar en una acción de encuentro, instalar procesos de apertura y no de cierre sobre el conocimiento/acción. Frente a los meta-relatos de la modernidad tendientes a una solución total y final a problemas que derivan de procesos históricos concretos, que continuarán siendo procesos incluso después de una intervención sobre ellos, trabajar su materialidad y su potencia requiere algo más urgente que una teoría, que ya hay disponibles; se requiere una

\footnotetext{
${ }^{1}$ NIETZSCHE, Friedrich. La Gaya Ciencia. Buenos Aires: Gradifco 2004, p. 138.
} 
metodología de interacción emancipadora que trabaje procesos de apertura en un sentido de profanación de lo estable.

El presente trabajo pretende explorar condiciones de respuesta a la distancia entre realidad y necesidades, entre derecho y derechos, elaborando una metodología que colabore en esa construcción. Se trata de una propuesta centrada no en un procedimiento objetivo abstracto ni en uno legal-formal sino en un "procedimiento participativo en el que los actores puedan discutir tanto sobre el mismo como sobre los bienes a los que se debe tener un acceso igual”2.

\section{CIENCIA, MÉTODO, REFLEXIÓN-ACCIÓN}

Hablar de metodología implica referirnos brevemente al paradigma moderno de las ciencias y a la relación sujeto/objeto, donde radica un nudo fundamental tanto de percepción de realidad como de reflexión/acción que dice relación con el tipo de prácticas que se desarrollan en la búsqueda del conocimiento de los contextos como en la lucha práctica por los derechos. Esa disyunción en el análisis es una parte esencial del método que de ella, la ciencia moderna, derivará.

Con base en la distinción kantiana entre mundo inteligible y realidad moral así como en la disyunción hegeliana sujeto/objeto, se construyó una forma de aproximación a la realidad sobre preconcepciones y definiciones estatuidas, que establece por un lado una mirada de extremos opuestos y excluyentes y por otra subsume a la realidad material y relacional a una noción de lógica abstracta y de leyes de orden antes que de movimiento y enlace. Es sin embargo un movimiento mucho más profundo que atraviesa todo el pensamiento de la modernidad, se trata de la constitución de un tipo de saber de reducción de lo real a una serie de leyes “descubiertas" y comprobables aisladamente, organizadas, jerarquizadas, que originalmente en disputa con el saber absoluto teologal devinieron en una epistemología que cosifica tanto los fenómenos como las relaciones a partir de la formalización de sus explicaciones que sustituyen a esa realidad.

\footnotetext{
2 HERRERA FLORES, Joaquin. El Proceso Cultural Materiales para la creatividad humana. Sevilla (Andalucía): Aconcagua Libros, 2005, p. 77.
} 
Este paradigma de la ciencia produjo su propio campo de saber así como su metódica, que reduciendo la polisemia cultural y natural elabora tipos ideales de acciones, modelos ideales sobre los cuales analizar esas acciones y delimitar sus sentidos, que permiten comprender, como resulta en Weber, que en el conocimiento de lo real defina "la aproximación científica en las Ciencias Sociales como aquella aproximación basada en la actividad estrictamente ideal y racional" 3 , que llevaron a Comte a definir a la sociología como una disciplina que "tiene un único problema y debe abarcar en un instante indivisible la secuencia del desarrollo histórico para hacer visible la ley que lo domina en su conjunto" ${ }^{4}$, a Durkaim a buscar una unidad moral que justifique lo social como un todo organizado y que aplicado al derecho llevó a Kelsen a sostener que "Una ciencia del derecho o una ética científica solo pueden tener por objeto el derecho positivo o una moral positiva. Dichas disciplinas describen normas positivas que prescriben o autorizan una conducta determinada y afirman que en tales condiciones tal individuo debe conducirse conforme a una norma dada" 5 .

Al menos desde 1636, con el Discurso del Método, se origina una genealogía de saberes, producción epistemológica y técnica que establece este paradigma de la respuesta única, la cosificación, la disyunción y la formalidad de los fenómenos que traspasada a los conflictos sociales, a las necesidades humanas y a los derechos, acaba por imponer su lógica formal en su lectura, prefiriéndolos sobre los criterios reales a materiales, provocando ceguera sobre las relaciones y movimientos que no solo constituyen los fenómenos y procesos sino que además, obviando por inciertos o volátiles, aquellos elementos que puedan constituir condiciones de posibilidad de cambio de los estados que originan esos conflictos y procesos.

“El Discurso del Método" afirmaba que "no habiendo más que una verdad en cada cosa, quien la encuentra sabe tanto como se puede saber"6, para lo cual debía seguirse un método de cuatro pasos ciertos consistentes en a) no admitir nada por verdadero hasta conocerlo con evidencia, b) dividir el problema en parcelas necesarias para su resolución, c) ordenar el conocimiento desde lo más simple hasta lo más compuesto, y d) hacer enumeraciones tan completas y revisiones tan generales para no omitir nada. Es decir una repetición hasta certificar la uniformidad abstractamente formalizada.

\footnotetext{
${ }^{3}$ CONDE, Fernando. Las perspectivas metodológicas cualitativa y cuantitativa en el contexto de la historia de las ciencias. In: DELGADO, Juan Manuel; GUTIÉRREZ, Juan (Orgs). Métodos y técnicas cualitativas de investigación en ciencias sociales. Madrid: Editorial Síntesis, 1995, p. 62.

${ }^{4}$ VARGAS E. V; LATOUR B.; KARSENTI B.; YAIIT-TOUATI F. El debate entre Gabriel Tarde y Emile Durkheim. EMPIRIA. Revista de Metodología de Ciencias Sociales. № 23, enero-junio, 2012, p. 191.

${ }^{5}$ KELSEN, Hans. Teoría Pura del derecho. Buenos Aires. Eudeba, 1999, p. 21.

${ }^{6}$ DESCARTES, René. El discurso del Método. Madrid: Ediciones Akal, S.A, 1989, p. 151.
} 
Si caracterizamos a la ciencia moderna como lo propone el siguiente cuadro ${ }^{7}$ podremos comprender de mejor manera lo señalado:

\begin{tabular}{|c|}
\hline Visión del mundo de la ciencia moderna. \\
\hline No hay relación entre hecho y valor. \\
\hline $\begin{array}{l}\text { La naturaleza se conoce desde afuera, y los fenómenos se examinan en } \\
\text { abstracción de su contexto (el experimento). }\end{array}$ \\
\hline El objetivo es el control consciente, empírico de la naturaleza. \\
\hline $\begin{array}{l}\text { Las descripciones son abstractas, matemáticas, únicamente aquello que } \\
\text { puede ser medido es real. }\end{array}$ \\
\hline $\begin{array}{l}\text { La Mente es algo separado del cuerpo; el sujeto es algo separado del } \\
\text { objeto. }\end{array}$ \\
\hline $\begin{array}{l}\text { El tiempo es lineal, en una progresión infinita; en principio podemos llegar } \\
\text { a conocer toda la realidad. }\end{array}$ \\
\hline La lógica es esto/aquello; las emociones son epifenoménicas. \\
\hline $\begin{array}{l}\text { Atomismo: } \\
\text { 1. Únicamente la materia y el movimiento son reales. } \\
\text { 2. El todo es nada más que la suma de sus partes. } \\
\text { 3. Los sistemas vivientes son en principio reducibles a materia } \\
\text { inorgánica; a final de cuentas la naturaleza está muerta. }\end{array}$ \\
\hline
\end{tabular}

En la práctica este modo de conocer/hacer realiza su movimiento de fragmentación y desapego, estableciendo "un dualismo absoluto entre la mente (res cogitans) y la materia (res extensa), que condujo a la creencia según el cual el mundo material puede ser descrito objetivamente sin referencia alguna al sujeto observador"8, de manera que la ciencia no se encuentra en el mundo sino fuera de ella para descubrirlo y expresarlo; el sujeto es un observador y constructor en un mundo externo que no es él pero del cual dispone, posee, usa y somete a discreción; la realidad es reducida a abstracción, a una comprensión unilineal y mono causal de los fenómenos, "que confía ciegamente en la interpretación del mundo derivada de relaciones de causalidad y más aún de relaciones mono causales, de las cuales deriva el

\footnotetext{
${ }^{7}$ BERMAN, Morris. El reencantamiento del mundo. Santiago: Editorial Cuatro Vientos, 1999, p. 22.

${ }^{8}$ MARTíNEZ MIGUÉLEZ, Miguel. Un Nuevo Paradigma Para La Ciencia Del Tercer Milenio. En Las Nuevas Utopías de la Diversidad. Lo deseable vuelve a ser posible. Santiago: Universidad Bolivariana, 2003, p. 231.
} 
concepto de eficiencia" 9 sin importar los costos colaterales, que en realidad son parte de un mismo proceso holísticamente activado y conectado.

Buscando combatir los determinismos de la filosofía natural y la religión se opuso una lógica cuyo fin es "explicar los principios y operaciones de nuestra facultad de razonamiento y la naturaleza de nuestras ideas" ${ }^{10}$, constituir una ciencia de lo cuantificable que servirá de base al giro mercantilista del cálculo sobre la riqueza de John Locke y la economía política subsiguiente. Una tecnología que se centra en su desarrollo interno antes que en los destinatarios; epistemología que opta por una erudición de lenguajes cerrados y optimiza las discusiones especializadas desconociendo los saberes no oficiales; una economía que considera que todo lo que obstaculiza su progresión de crecimiento una externalidad a remover; una política profesionalizada hasta la exclusión de los votantes representados; un derecho centrado en la aplicación formal de la normatividad y no en los sujetos de derecho y sus necesidades; una lógica de la alienación que divide al sujeto entre el discurso de la objetividad y la vivencia de la subjetividad. "La ciencia moderna existe en un equilibrio delicado: entre la ignorancia relativa del objeto del conocimiento y la ignorancia relativa de las condiciones del conocimiento que pueden obtenerse del mismo"11. Un vacío que parece imposible de llenar dentro de sus propios límites porque en la práctica los sujetos mismos que participan de los nudos y mecanismos de salida de los conflictos sociales se encuentran por un lado escindidos y por otro abstraídos de su contexto toda vez que las conexiones entre estos espacios ya no son materiales sino lógico formales. En el paradigma hegemónico “La plausibilidad empírica es una cuestión de demostración de las conexiones lógicas entre fenómenos que pueden ser concretamente descritos”12, todo lo que sea azar o peor aún condición de posibilidad de una diferencia es clausurado como opción lógica a pesar que pueda ser justificada técnicamente desde otro punto de referencia.

En lo jurídico, especialmente en cuanto al contenido de los derechos ha ocurrido una cosa similar. "La idea moderna sobre los derechos humanos proviene de una oposición entre naturaleza y cultura"13, la disyunción operativa, el cierre por oposición; una división sustentada sobre el concepto del orden formal de las cosas y de los regímenes. El sistema jurídico moderno

\footnotetext{
${ }^{9}$ ELIZALDE, Antonio. Desarrollo Humano y Ética para la sustentabilidad. Santiago: PNUMA- Universidad Bolivariana, 2003, p. 148.

${ }^{10}$ HUME, David. Tratado de la naturaleza humana. Tomo 1. Madrid: Calpe, 1923, p. 4.

${ }^{11}$ SANTOS, Boaventura. Crítica de la Razón Indolente. Contra el desperdicio de la experiencia. Bilbao. Editorial Descleé de Brouwer, S.A. 2003, p. 91.

${ }^{12}$ SENNETT, Richard. El declive del hombre público. Barcelona: Ediciones Península, 2002, p. 106.

${ }^{13}$ SENNETT, Richard. El declive del hombre público. Barcelona: Ediciones Península, 2002, p. 206.
} 
propone un actor (el individuo propietario), un modelo de sociedad (liberal contractualista), una historia (la del liberalismo) y una forma de satisfacer las necesidades de los individuos (el intercambio comercial capitalista y la acumulación de bienes) y como todo sistema, requiere mecanismos que aseguren la mantención de sus supuestos y de sus relaciones. Ese método de la subsunción de la realidad en la norma, del razonamiento jurídico entendido como un juego dogmático del texto, en su reduccionismo epistemológico, acaba por alcanzar a los derechos y reducir el conflicto jurídico a un conflicto legal, que declara ilegal lo que se aparta de la norma. Como lo señala Pietro Barcellona:

lo que el derecho realiza en su configuración moderna parece casi un evento milagroso en el desarrollo de las sociedades humanas: unir y separar a la vez, mantener como posible la división la atomización de la sociedad concebida como sociedad de individuos independientes $y$, al mismo tiempo, realizar su unificación, alcanzar esa unidad que permite identificar la sociedad como código.

Contra esa unificación por identificación los conflictos de necesidades, estos no resultan nunca del todo resuelto por el choque de la diversidad contra la uniformidad de respuesta técnica y el necesario orden centrípeto o centrífugo de las respuestas de política pública a las necesidades, ya sea estableciendo derechos sociales generales o abandonándolas a la dirección no azarosa del mercado que elije entre quienes pueden pagar y quiénes no. Como bien lo expresa la teoría de sistemas que no es la lógica del derecho reflexivo sino otro régimen de regulación, ese orden solo puede resolver los conflictos suprimiendo (teórica o prácticamente) o reprimiendo el motivo de esa irritación debe recurrir a una reafirmación de su contenido y no a una innovación de respuesta, obliga a pensar en el cómo enfrentar ese problema desde una complejidad que produzca la apertura del conocer/hacer hacia soluciones y no el cierre de respuestas en sus formas abstractas pre definidas de lo que debe ser.

La respuesta inclusiva no se ubica ni se dispone, en consecuencia, en el reduccionismo epistemológico y metodológico sino en los procesos de apertura. Mientras que la matematización ha dado origen a una producción cultural y metódica del orden, la necesidad, en tanto desorden expresado, no requiere ser reprimido ni readaptado porque en cambio propone la potencialidad y la posibilidad de las acciones en los espacios y en las interacciones. No es la repetición del método unívoco de la subsunción ni la repetición de la ritualidad de los formularios la que construirá una solución inflexiva nueva y renovadora del estado de situación que origina el

\footnotetext{
${ }^{14}$ BARCELLONA, Pietro. El individualismo propietario. Madrid: Editorial Trotta S.A, 1996, p. 25.
} 
problema sino la construcción de alternativas plurales en procesos de apertura de relacionamientos innovadores. Por un lado "La pluralidad de opinión es necesaria para el conocimiento objetivo, y un método que fomente la pluralidad es, además, el único método compatible con una perspectiva humanista" ${ }^{15}$, por el otro la apertura se revela inflexiva de la tensión del orden:

Nos incita a investigar, tanto la relación cuanto la distinción con el entorno, más la asociación compleja entre dependencia y autonomía, apertura y cerramiento, que la alternativa entre estos términos; más la reorganización que la organización, más la praxis que la estructura; además, toda concepción de sistema abierto nos conduce a concebir su ecosistema de inscripción y a elaborar un metasistema de referencia. ${ }^{16}$

\section{EMANCIPACION Y NUEVOS PARADIGMAS}

El sistema mundo que se nos impone en su ideología de pensamiento único, en su movimiento de economía global, naturaliza la extensión del mercado no ya como sistema de (auto)regulación del intercambio de bienes y servicios sino como lógica íntima y vital de la compra y venta de todo lo existente, reduce el quehacer humano a relaciones comerciales como valor único o al menos hegemónico de la cultura; en que todo conocer, todo saber, toda creación incluso, es reducida al valor de la transacción.

Desde la nuda vida a la subsistencia todo se subsume en este movimiento que organiza la manera de aproximación a la cotidianeidad. "Una consecuencia fundamental de ésta realidad consiste en el enorme énfasis que el sistema mundial moderno pone en las virtudes de lo nuevo"17, de manera que con ello todos los lazos relacionales son presentados como obsoletos si no generan novedad. Ello, sobre el entramado social produce un desgaste anticipado de toda forma de gestión sobre sus asuntos, sus problemas, sus crisis; llevado esto a las necesidades, a los conflictos, a las constantes readecuaciones sobre un mismo entorno y los mismos participantes pone en riesgo de dejar entregar todo hacer a esa lógica novedosa de lo comercializable y lo instantáneo. Toda crisis del hacer humano así no alcanza a ser percibida sino que queda oculta en la trama del flujo de lo novedoso, y se nos propone, como las técnicas del Fondo Monetario Internacional que permean desde las macroeconomías hasta los programas sociales, una receta de gestión individual para la disolución en el flujo que no alcanza a

\footnotetext{
${ }^{15}$ FEYERABEND, Paul. Tratado contra el método. Madrid: Editorial Tecnos, 2000, p. 29.

${ }^{16}$ MORIN, Edgar. El método. La naturaleza de la naturaleza. Madrid: Cátedra, 1999, p. 240.

17 WALLERSTEIN, Inmanuel. Geopolítica y geocultura. Ensayos sobre el moderno sistema mundial. Barcellona: Kairos, 2007, p. 227.
} 
constituirse en un colectivo donde, a diferencias de las unidades de valor financiero, no existe agregación uno a uno sino contextual y colectiva, así suene disonante para algunos.

Pensar de otro modo requiere ser capaz de salir de esa trampa, de esa especie de clausura de mirada y posibilidad en que por momentos los pensamientos críticos sufren. Se requiere una voluntad no solo para resistir y luchar sino sobre todo para imaginar, inventar, combinar y recombinar los instrumentos, las experiencias y los ensayos de que disponemos. Esa actitud intelectual es a su vez una actitud práctica, fáctica, la cual no puede hacerse desde la abstracción sino que requiere de una materialidad y una finalidad, lo que se consigue teniendo como principio algo más urgente que una teoría: una metodología que nos lleve a síntesis de experiencia que puedan constituir saberes y no al revés.

Proponemos para ello una metodología acumulativa-integrativa de cinco pasos: Hacer visible lo real, Cambiar la mirada, Pensar de otro modo, Cambiar la emocionalidad y Cambiar la interacción.

\subsection{Hacer visible lo real}

La realidad es un enunciado no una definición. Ni un momento ni un hecho sino un estado-situación-proceso en mutación y construcción permanente pero no lineal, múltiple, incluso contradictoria. Cada vez que nos enfrentamos a un problema no puramente teorético nuestra principal dificultad consiste en determinarla.

El principio de incertidumbre según el cual es imposible calcular simultáneamente la velocidad y la posición de una partícula no es privativa de la física. Lo mismo ocurre con la imposibilidad de evaluar a un tiempo la realidad y el significado del acontecimiento en la información, de diferenciar las causas de los efectos en un proceso complejo. ${ }^{18}$

En esta opacidad epistemológica y práctica que denunciamos nuestro principal obstáculo para pensar/actuar en una perspectiva de construir calidad y dignidad de vida próxima a la vez que global es que sufrimos una crisis de percepción respecto de eso que llamamos realidad, acerca de las causas verdaderas, los responsables y los caminos de solución de nuestros problemas. La invisibilización de las causas de los problemas se suma a nuestra carencia de instrumentos y mecanismos de mirada diferente y divergente a los de la ciencia del objeto. Adoctrinados sobre la idea de una verdad que solo es aprensible mediante los instrumentos y procedimientos formales de la ciencia ejecutada por "especialistas" perdemos de vista nuestro

${ }^{18}$ BAUDRILLARD, Jean. El Intercambio Imposible. Madrid: Ediciones Cátedra, 2000, p. 26. 
entorno, pendientes de la verdad que se encontraría en otro lado y es dicha por otros; si quienes saben y observan son otros, degradamos y trivializamos nuestra propia capacidad de mirar, actuar y cambiar aquello que entorpece o impide nuestro desarrollo.

Nuestra Mirada sobre la realidad se constituye a partir de mapas que describen un tipo de territorio, que si bien no se corresponden totalmente con el tipo de vivencias que constituyen nuestro operar en el mundo, sin embargo nos resultan extremadamente seductores, por el escaso nivel de exigencia y rigor que nos demanda su aceptación. ${ }^{19}$

Se trata de un verdadero secuestro instalado de la realidad, que nos descentra en nuestra posibilidad de conocimiento y acción. "Tendemos a reflexionar sobre los diferentes absolutos que predican un ser al margen de lo que realmente somos" ${ }^{20}$ enajenándonos, expropiándonos de nuestra subjetividad de lo posible, afectando nuestra propia estructura de construcción neurológica, ritualizando nuestros comportamientos, sometiéndonos a una repetición de las conductas y la forma de mirar que nos enceguece respecto de nuestra posición y disposición en las estructuras y narraciones de lo real.

Para actuar sobre la realidad, es decir sobre nosotros dentro del contexto relacional que nos rodea y que co generamos, así como para hacer una cotidianeidad en que los derechos sean una realidad más allá de los enunciados formales, para realizar un acto instituyente de los sujetos como sujetos constituyentes de sus propios derechos y de su propia realidad, la primera acción es precisamente romper ese bloqueo, pasar por sobre nuestras propias limitaciones de percepción y ser capaces de observar y no solo de mirar; desbloquear la opacidad de nuestro entorno a la que se nos somete. Se trata de sacar a la luz las situaciones en que nos encontramos, las tramas en que nos desenvolvemos y envuelven, no solo de exponer un estado, una situación, un proceso, con pretensión de objetividad, como en una fotografía en la mesa de un cientista social, sino que de una acción más profunda y generadora de sentido, un proceso de producción de información no para informatizarla y ritualizarla, sino para sentirnos en ella y en nuestro entorno, un conocimiento que nos re-contextualice y de sentido a la capacidad de estar y accionar sobre los espacios de nuestra cotidianeidad. Sin realidad material todo lo que se diga sobre ella es ante juicio y concepto y nos priva de conocer los puntos exactos para la deconstrucción y cambio de un estado/proceso.

\footnotetext{
${ }^{19}$ ELIZALDE, Antonio. Desarrollo Humano y Ética para la sustentabilidad. Santiago: PNUMA- Universidad Bolivariana, 2003, p. 34.

${ }^{20}$ HERRERA FLORES, Joaquin. Hacia una visión compleja de los Derechos Humanos. En El vuelo de Anteo. Derechos Humanos y Crítica de la razón liberal. Editorial desclée de Brouwer, S.A. Bilbao, 2000, p. 31.
} 
Se trata de develar no solo hechos sino las situaciones, las relaciones, de hacer visibles las causas y los causantes de ellas, sus nudos de mantención y perpetuación para actuar sobre ellos, de determinar las causas reales de los problemas, no los antejucios que sobre ellos tenemos; la posición y la disposición de los sujetos involucrados, las necesidades y los intereses en juego. Las hipótesis no son la realidad ni la respuesta, son la trama que entre uno y otro punto que se despliega en el conocer lo que nos interesa.

\subsection{Cambiar la mirada}

Sin embargo no basta hacer visible lo real para provocar cambios. Conocer la realidad no garantiza una mejor posición respecto de ella, sino que puede significar una ceguera de cuño distinto. "Los órganos humanos únicamente pueden recibir noticias sobre diferencias, y esas diferencias para ser perceptibles, deben estar codificadas en sucesos que acontecen en el tiempo (o sea, deben estar codificadas en cambios)" ${ }^{21}$, de manera que mirar repitiendo ritos viejos inmoviliza más que cambia; la neurobiología nos enseña que ante la ritualidad los organismos se adecúan.

Se requiere una mirada que indague en los límites de esa realidad, que vaya de los polos manifiestos de los acontecimientos a la trama de proceso, a la deriva que se verifica entre ellos, de lo formal a lo contextual. Desbloquear el proceso racional, cultural, antropológico y político de ceguera de percepción requiere iniciar la mirada en el acto para inmiscuirse en su devenir. Ello entraña -a lo menos - tres movimientos simultáneos:

Primero, pasar de lo uno a lo múltiple, disponer el pensamiento para una perspectiva de desborde la unicidad. Del fenómeno como objeto a su descubrimiento en tanto procesos y entrecruzamientos simultáneos, de las fuentes únicas a la pluri-producción de lo real; de las verdades completas, reveladas y totales a la constatación del acierto/error/experiencia como ejercicio de producción; de la monocausalidad a la complejidad. "La ontología de occidente estaba fundada sobre entidades cerradas, como ser la sustancia, la identidad, la causalidad (linear), el sujeto, el objeto"22 y de lo que se trata es de romper precisamente con esa construcción de lo unívoco lineal para observar pluralidad y complejidad. Lo que queremos ocurra muchas veces ya está aconteciendo, es nuestro lente el que no logra captar esa totalidad ni integrarla. No hay transformación en lo lineal, solo montaje.

\footnotetext{
${ }^{21}$ BATESON, Gregory. Espíritu y Naturaleza. Buenos Aires: Amorrortu Editores, 1990, p. 64.

${ }^{22}$ MORIN, Edgar. Introducción al pensamiento complejo. Séptima Edición. Barcelona: Editorial Gedisa S.A., 2004, p. 82.
} 
Segundo, mirar no solo el eje individual sino la posibilidad de lo colectivo. La observación y análisis desde el prisma individual se encuentra poderosamente arraigada, el individuo como concepto y dispositivo es la clave del edificio de la modernidad liberal así como sus límites e insuficiencias. Dividir, fragmentar, ordenar, controlar, clasificar, burocratizar y estandarizar es la forma de la construcción social y la práctica sistémico-política: "El sistema produce individualización, pero no individualidad, pues su referente es el comportamiento y no la acción, el obrar intencional”23. Una práctica que se pretenda distinta en tanto satisfacción de las necesidades más allá de la formalidad requiere tanto una observación como una acción colectiva y no solo formal respecto de los sujetos. "Entre la forma del sujeto y la realidad del individuo se abre un abismo" 24 y cerrarlo implica tener presente en la mirada inicial la necesidad de lo colectivo como punto de inicio, proceso y llegada. No es posible imaginar nuevas prácticas si no se trasciende de los parámetros individuales

No tenemos libertad para existir meramente en la vertiente de nuestro yo, de nuestra identidad, ni tampoco solo en la vertiente del mundo llamado real. Todo nos viene de esta adversidad, de esta complicidad gemelar. El destino se comparte, como el pensamiento, que nos viene del otro. Cada cual es el destino del otro. No existe el destino individual. ${ }^{25}$

Tercero, producir parámetros distintos a la finalidad liberal y la traducción de sus formas, lo que implica releer, revisar, repensar.

\subsection{Pensar de otro modo}

Además de las consecuencias cognitivas de adoptar otra mirada plantearse como desafío propuestas alternativas a los modelos vigentes requiere superar, trascender y replantearse el paradigma moderno de la atomicidad individual, de la fragmentación, del progreso y acumulación lineal. Enfrentar problemas como los derechos humanos o las necesidades fundamentales, como un hecho no restringido a la individualidad requiere discernir de formas distintas a las hasta ahora admitidas, legitimadas y practicadas desde las instituciones.

23 BARCELLONA, Pietro. Postmodernidad y Comunidad. El regreso de la vinculación social. Madrid: Editorial Trotta S.A, 1992, p. 33.

${ }^{24}$ BARCELLONA, Pietro. El individualismo propietario. Madrid: Editorial Trotta S.A, 1996, p. 139

${ }^{25}$ BAUDRILLARD, Jean. El Intercambio Imposible. Madrid: Ediciones Cátedra, 2000, p. 87. 
Pensar de otro modo requiere cambio de métodos y de de paradigma, una "inversión del paradigma clásico que se identificaba con la entropía y la evolución degradante, donde la relación causa efecto, en sentido unidireccional, constituiría su ley fundamental"26.

Ante un orden social en que la vinculación entre sujetos se realiza por vía contractual; con una noción de riqueza que demanda acumulación; un uso lineal del tiempo que desecha la vivencia del presente y a su vez descuida los efectos del futuo; una idea de ciencia y experticia centrada en la técnica; un saber erudito oficializado que desecha, esconde o funcionaliza los saberes locales; una concepción de lo público centrado en la administración burocrática que concibe a los ciudadanos como usuarios/clientes; una gestión del orden como control; una jerarquía de la desintegración, resulta necesario una inversión de ese orden para su reconstrucción. No para oponer lo colectivo a lo individual como una fractura sino para afirmar otra disposición de valores, conceptos y relaciones distintas en su lógica y en su mecánica.

De una manera quántica - que implicó adoptar una otra y distinta concepción de la materia y con ello de la naturaleza- se requiere una nueva posición de pensamiento que se replantee esa relación y las relaciones subjetivas e ínter subjetivas que consigo traen; una gestión de la administración, la economía, los procesos y del tiempo diferente a la linealidad, abierta a la complejidad. "En vez de eternidad, tenemos la historia; en vez de determinismo, la imprevisibilidad; en vez de reversibilidad, la irreversibilidad y la evolución; en vez del orden, el desorden; en vez de la necesidad, la creatividad y el accidente" ${ }^{27}$, lo que significa adoptar perspectivas, definiciones y decisiones que aun cuando parezcan apenas un matiz diferentes, son en su diversidad y multiplicación radicalmente distintas. "Un nuevo paradigma exige el derrocamiento del viejo, y no precisamente una adición a las teorías precedentes" ${ }^{28}$. Hay signos que pueden mostrarnos un camino.

El carácter de proceso en construcción es la primera y fundamental característica de ésta emergencia. Como señala Baudrillard "En general, las cosas se hacen y después se organizan retrospectivamente en una idea de proyecto, en una idea de voluntad que sanciona a posteriori el acontecimiento de la misma forma que se construye el relato del sueño en el momento de

\footnotetext{
${ }^{26}$ MARTínEZ MIGUÉLEZ, Miguel. Un Nuevo Paradigma Para La Ciencia Del Tercer Milenio. En Las Nuevas Utopías de la Diversidad. Lo deseable vuelve a ser posible. Santiago: Universidad Bolivariana, 2003, p. 236.

${ }^{27}$ SANTOS, Boaventura. Crítica de la Razón Indolente. Contra el desperdicio de la experiencia. Bilbao. Editorial Descleé de Brouwer, S.A. 2003, p. 67.

${ }^{28}$ MARTÍNEZ MIGUÉLEZ, Miguel. Un Nuevo Paradigma Para La Ciencia Del Tercer Milenio. En Las Nuevas Utopías de la Diversidad. Lo deseable vuelve a ser posible. Santiago: Universidad Bolivariana, 2003, p. 236.
} 
despertar"29es en razón de ello que no se trata de un proyecto sino de una emergencia, lo que nos obliga a estar atentos a su captura. Lo que queremos pase probablemente ya está ocurriendo, pero se requiere individualizar, reconocer, asumir, activar y potenciar estas pistas. En el agotamiento o crisis del paradigma moderno puede verificarse una cierta reconstrucción de teorías y experiencias emancipatorias pasadas pero no desde la búsqueda de una totalidad opuesta sino como una experiencia de construcción permanente de subjetividad, individual y colectiva, actual y constante. Se trata de un proceso complejo, inestable e incompleto a la vez, en producción dinámica y por lo mismo fuerte y posible, que deja atrás la pretensión de totalidad racionalista y científica para construirse en una perspectiva de diversidad, fragmentación y reconstrucción que se otorgue sentido y coherencia en su propio movimiento.

Asumir un paradigma emergente implica señalarlo como realidad. Nombrar, decir, hacerlo hablar y no solo "denominar" éste paradigma es una acción estratégica y de creación. "Por esto, el lenguaje es también nuestro punto de partida, nuestro instrumento cognitivo y nuestro problema" 30 a asumir, en una perspectiva de uso, de apertura, de afirmación de construcción de realidad en una perspectiva no lógico-racional sino de juego y de metáfora. En el lenguaje "jugamos juegos con palabras" decía Wittgenstein, por lo que se trata de afirmar la emergencia y existencia neoparadigmática como un acto de afirmar lo propio. La retórica del y en el lenguaje, como campo y posibilidad de construcción de la realidad, de las opciones y de las soluciones, es parte esencial de éste hacer más allá de las denominaciones de los expertos para abrir nuevos campos de realidad, de trabajo, de acción. "En general, la retórica científica tiene en vista utilizar apenas la prueba lógica y, por consiguiente, su principal característica es negar que sea retórica" 31 transformándola en "verdadera", en un saber impuesto por el poder de quienes controlan el debate y la emisión del discurso. Para evitar caer en el juego de la lógica cerrada de la razón moderna y repetir el pensamiento binario y la dialéctica de oposición de suma cero, asumir el problema del lenguaje en la perspectiva de la creación y no de la imposición implica hacerse cargo de su carácter de instrumento. Si "todo lo que es dicho es dicho por alguien" ${ }^{32}$, esos discursos de cierre de procesos son interesados y parciales. Evitar procesos de cierre y asumir una apertura de hacer social no impositiva resulta esencial.

\footnotetext{
${ }^{29}$ BAUDRILLARD, Jean. El Intercambio Imposible. Madrid: Ediciones Cátedra, 2000, p. 88.

30 MATURANA, Humberto; VARELA, Francisco. El árbol del conocimiento. Las bases biológicas del entendimiento humano. Buenos Aires: Editorial Lumen, 2003, p. 13.

31 SANTOS, Boaventura. Crítica de la Razón Indolente. Contra el desperdicio de la experiencia. Bilbao. Editorial Descleé de Brouwer, S.A. 2003, p. 113.

32 MATURANA, Humberto; VARELA, Francisco. El árbol del conocimiento. Las bases biológicas del entendimiento humano. Buenos Aires: Editorial Lumen, 2003, p. 13.
} 
Una característica esencial del nuevo paradigma es no negarse a las denominaciones sino abrir la posibilidad de llamarlas de maneras nuevas y múltiples, invertidas y revueltas, en un lúdico y emotivo.

La realidad no se conoce ni se construye solo por medio de metodologías cuantitativas o cualitativas sino en y por medio de procesos participativos, abiertos y argumentativos que usan técnicas plurales y dúctiles. Hay que asumir, desarrollar, ejercer y construir(se) en un discurso no impositivo sino argumentativo. "Es inherente al discurso argumentativo el hecho de que esa invención nunca será completa y nunca alcanzará un punto de irreversibilidad”33, lo que precisamente es la base para la reinvención constante de la realidad y no la repetición de una realidad global impuesta. Si como sostenía Wittgenstein "Los límites de mi lenguaje significan los límites de mi mundo" ${ }^{34}$ nombrar y usar los nombres lúdica y metafóricamente es una forma de reapropiarse del mundo, su cotidianeidad y vecindad hasta la globalidad, reinstalándose en él soberanamente.

Éste paradigma emergente no es ni moderno ni liberal. Es no moderno en cuanto busca superar los límites de la razón moderna desde un saber no monista sino pluralista, que rompa con la lógica binaria antinómica que ordena al mundo en opuestos (naturaleza/sociedad, civilizado/salvaje, bueno/malo, riqueza/pobreza, estado/sociedad, sujeto/objeto, razón/emoción, etc). Pero además lo es en el sentido que no pretende ser ni totalizante ni una verdad universal a priori sino que construirse reconociendo saberes diversos e incluso no formalizados. De la misma forma que no pretende centrar la producción de lo social en la economía ni en el intercambio lucrativo de bienes, a través del contrato como exclusivo y privilegiado vínculo social; fuera del capitalismo escapa de ser liberal al no sustentarse en una perspectiva antropológica individualista.

Así como es posible establecer que la conjunción de diversos factores y órdenes se superpusieron hasta configurar la matriz sociocultural de la modernidad occidental dominante, es también posible visualizar una perspectiva distinta, una inflexión hacia lo plural y lo complejo. La confluencia de ciencia, técnica, lógica dicotómica y universalista, capitalismo y estado como forma "ideal" e "instrumental" de configurar un orden permite entender muy claramente como hemos llegado a existir en el centro de un modelo de crisis institucionalizada, que se presenta como estado natural pero que muestra rasgos de agotamiento que por si solos no

\footnotetext{
${ }^{33}$ SANTOS, Boaventura. Crítica de la Razón Indolente. Contra el desperdicio de la experiencia. Bilbao. Editorial Descleé de Brouwer, S.A. 2003, p. 125.

${ }^{34}$ WITTGENSTEIN, Ludwig. Tractatus lógico-philosopicus. Madrid: Alianza Editorial, 2009, p. 111.
} 
aseguran su quiebre, empero qué parece indispensable superar. En esa convergencia histórica, el hecho que

nuestra sociedad capitalista y burguesa se erija sobre la piedra fundamental del derecho de propiedad como dominio irrestricto sobre la tierra y los medios de producción por parte de individuos, explica por que no puede imperar en ella otra forma de organización societaria que no sea la gubernamental: al dualismo propietario-proletario le corresponde el dualismo gobernante-gobernado. ${ }^{35}$

Y ello nos mantiene presos de esa tensión, al punto que disuelve la posibilidad del gobernado como sujeto ciudadano y obliga a replantearse al sujeto constituyente y su soberanía no solo dentro de las relaciones económicas y políticas tradicionales. La superación del individuo, no su desaparición ni subsunción, es un vértice de acción antropológico neo paradigmático.

Si en los orígenes de la modernidad liberal, "asumir una antropología individualista para poner en marcha una nueva constitución social" ${ }^{36}$ fue el motor y tarea de los principales teóricos de éste nueva orden en construcción, de manera que constituir a ese sujeto como la piedra angular de un sistema permitiera construir un tipo de sociedad donde un supuesto contrato social servía para desafectar a todos los súbditos y vincularlos de otra manera, pensar en un nuevo paradigma ni moderno ni liberal implica crear, recrear y hacer visibles redes y relaciones sociales distintas a las de la esfera intersubjetiva individual. Relaciones no solo identidades.

Se trata de instituir sujetos en relaciones múltiples en su comunidad, no solo de intercambio de bienes; no formales sino experienciales, que los vinculen en la naturaleza, con sus objetos de conocimiento, con sus entornos geográficos, con sus acciones económicas y con sus congéneres. Se trata de construir imaginarios y técnicas de intercambio de bienes no en la lógica del valor de cambio sino del valor de uso; de vínculos incluso formales que apelen no a la igualdad formal sino a la igualdad real, sus necesidades de complementación, de equilibrio y de responsabilidad mutua, cooperativa y colectiva; con una percepción, una conciencia y una acción responsable hacia ellos mismos y su entorno natural y social; con una fuerte actitud relacional, flexible, sinérgica y constructiva.

La racionalidad moderna vuelve abstractas y funcionales todas las relaciones, entrega la solución de problemas éticos y políticos a soluciones técnicas politizadas en esa asepsia, coloca a

\footnotetext{
${ }^{35}$ CAPPELLETTI, Angel. La Ideología Anarquista. Santiago: Ediciones Espíritu Libertario, 2004, p. 81.

${ }^{36}$ BARCELLONA, Pietro. Postmodernidad y Comunidad. El regreso de la vinculación social. Madrid: Editorial Trotta S.A, 1992, p. 43.
} 
las personas en calidad de objetos. Trabajar en un sentido antropológico post individual implica imaginar un sentido de acción constructor de relaciones y no de aislamientos intersubjetivos teóricamente vinculados en una ciudadanía por mera representación pasiva, inmersa en tramas de actos de consumo alienados y racionalmente siempre dispuesta al utilitarismo y al contrato. Se trata de construir esos lazos en perspectivas colaboracionistas no fragmentarias, reforzando una subjetividad que sea identidad compartida, que conjugue lo público, lo privado y lo íntimo, desarrollada en redes de lenguaje y prácticas colectivas, tiempo social y espacio público. "Lo que parece requerirse es un fortalecimiento de los procesos estrictamente sociales que permiten transformar la diversidad de subjetividades en acción colectiva"37; en definitiva una mirada diversa e integradora, no solo multicultural sino esencialmente intercultural. Como lo ha dicho Joaquín Herrera,

Cuando hablamos de "lo cultural", pues, nos referimos al proceso que permite justificar, criticar, legitimar o rechazar el conjunto de relaciones dadas entre los seres humanos y la naturaleza, -tanto externa (naturaleza física) como interna (naturaleza psíquica)- y entre los diferentes grupos sociales que existen en un momento histórico determinado (naturaleza social) ${ }^{38}$

La modernidad en tanto paradigma es una construcción que se pretende universal y actúa en consecuencia, utilizando el instrumento Estado para imponerse hacia adentro y afuera de las fronteras, ya sea por procesos imperialistas y colonizadores que tienen en común, hasta el día de hoy en que el capital globalizado refuerza ese empeño de imponer como único proceso de civilización, una razón occidental monista, capitalista excluyente y militarista que es presentada como estado natural de la sociedad, el llamado fin de la historia. "Esa violencia cultural que divide al mundo entre los cultos y los incultos, entre los racionales y los irracionales, entre civilizados y bárbaros" 39 es a la vez un elemento central y constituyente de la forma dominante de mirar y dominar el mundo como de reproducirlo, que tiende a la uniformidad que se maneja y disuelve en el acto del mercadeo.

\section{7}

FOERSTER, Rolf. Sociedad Mapuche y Sociedad chilena. En Polis, Revista de la Universidad Bolivariana. Volumen 1, $\mathrm{N}^{\circ}$ 2. Santiago: Universidad Bolivariana, 2001, p. 115.

${ }^{38}$ HERRERA FLORES, Joaquin. Hacia una visión compleja de los Derechos Humanos. En El vuelo de Anteo. Derechos Humanos y Crítica de la razón liberal. Editorial desclée de Brouwer, S.A. Bilbao, 2000, p. 37.

${ }^{39}$ HERRERA FLORES, Joaquin. Hacia una visión compleja de los Derechos Humanos. En El vuelo de Anteo. Derechos Humanos y Crítica de la razón liberal. Editorial desclée de Brouwer, S.A. Bilbao, 2000, p. 65. 
Pensar de otra forma implica deconstruir y repensar la forma de esas relaciones, no solo para reconocer las culturas en una muestra de las expresiones disímiles o para hacerlas operar conjuntamente, como hasta ahora, en espacios físicos, políticos, mentales, ideológicos y psicosociales paralelos, que mantienen las divisiones relacionales de dominio y exclusión y/o las enfrentan o confrontan solo en el reconocimiento de la diversidad, sino para pensar distintas formas de relaciones que asuman que la cultura es un punto de partida para una co-construcción de la realidad que establezca posibilidades de posición equitativas y cooperativas, de reconocimiento efectivo y no meramente formal, que provoque redes y relaciones efectivas y afectivas no coloniales, no dominantes ni excluyentes, sin privilegiar una forma cultural por otra sino que intentando articular puntos de construcción de de procesos que permitan remover las estructuras materiales y culturales que impidan la satisfacción de las necesidades. Pensar de oto modo no es pensar una mega cultura que las integre a todas sino metodologías que sean puentes de construcción en el sentido antes señalados.

Pero además de reconocer el corte integración/exclusión cultural y las dominaciones que de allí emanan, pasar a lo plural y complejo obliga a construir un paradigma no sexista, que asuma por tanto la igualdad de especie en la diversidad de subjetividad y que asuma, rescate y potencie de lo que las feministas denotaron como "ética del cuidado ajeno". Los aportes del movimiento feminista por la integración dicen relación con la superación de los binomios masculino/femenino y público/privado como formas de dominación transversales que atraviesan la totalidad de los ordenes sociales, de manera que se trata de un punto clave de pensamiento y acción.

Esto se refiere no solo a una redefinición de roles y redistribución de responsabilidades privadas y trabajo doméstico sino de construir una perspectiva políticamente distinta al orden patriarcal de dominación, posesión y disposición de los más débiles; de construir un ejercicio del poder centrado en una ética finalista de dignidad, en que los fines y los medios sean respetuosos, cooperativos, emancipadores; una ética que tiene como principio que lo privado merece el mismo respeto que lo público o, mejor, que lo público no puede ejercerse sobre el desprecio de lo privado. De ésta forma, rompiendo con la lógica binaria que al polarizar las posibilidades esconde lo real, se trata de redibujar el mapa de las relaciones humanas centrándose en la cooperación y el cuidado del otro en todos los espacios sociales, no solo entregando éste cuidado a la familia o a las cada vez más difusas instituciones de seguridad social. Se trata de formar una conciencia de interdependencia en el cuidado y de autocuidado para la interdependencia, en un proceso de reaprendizaje relacional a partir de uno mismo. 
Como señaló Focucault, un énfasis en la perspectiva social del ocúpate de ti mismo antes que el individualismo autoreferente del conócete a ti mismo, desvinculado de los intercambios en que nos encontramos, "por que al enseñar a la gente a ocuparse de sí misma, le enseña a ocuparse de si misma con la ciudad"40.

Trabajar en un paradigma no moderno ni liberal implica poner la participación, la solidaridad y la colaboración en el "corazón" de éste pensar hacer. Participación ya no como un carácter formal o meramente procedimental.

El enfoque del concepto de participación y de la forma como nos hemos acostumbrado a referirnos a él en el fenómeno social y político del desarrollo de la sociedad, responde precisamente a una instalación de una manera de leer la participación en base a la lógica dominadora formal perteneciente al paradigma del patrón cultural individualista. ${ }^{41}$

Un nuevo paradigma requiere establecerla como un fin en si misma, que produzca nuevos resultados hacia el interior y al exterior de quienes realizan la participación, entre diversos grupos o entidades abocadas a la construcción de sus derechos y satisfacción de necesidades humanas. Como señala Manuel Jacques se ha reducido el concepto a falsos satisfactores de participación, designando a la organización, la información o la movilización social como espacios y acciones participativas. Si bien es cierto lo son, poner a la participación como un fin en si mismo implica un proceso de pensamiento diferente en que cada vez que se participa se hace no solo para algo sino que se constituye un espacio en sí y para sí. "La construcción de este espacio del paradigma de inter-dependencia, que instituye la cultura del nosotros, importa el desarrollo de categorías éticas coherentes y correspondientes a este diseño inter-dependiente. En este sentido la participación es más que un instrumento sino que debe ser entendida y practicada como el proceso mismo esencialmente relacional y posicional, que se constituye en la medida que contiene esfuerzos parciales de información, opinión, expresión, movilización y decisión, articulado siempre en torno al criterio de decisión como elemento de cierre y completud del proceso.

La solidaridad es otra clave de éste nuevo paradigma. No filantropía o caridad sino “acciones efectivas de solidaridad" en el sentido de construir espacios sociales en donde se remueven los obstáculos materiales, políticos, ideológicos y culturales que obstaculizan la satisfacción de las necesidades a la vez que articulan esfuerzos y sujetos que se interrelacionan.

\footnotetext{
${ }^{40}$ FOUCAULT, Michel. Tecnologías del Yo. Barcelona: Ediciones Paidos Ibérica S.A., 1995, p. 52.

41 JACQUES PARRAGUÉZ, Manuel. Modelo de participación por afección: un modelo para el desarrollo de la ciudadanía local. Disponível em: www.revistapolis.cl/5/jac.htm
} 
La solidaridad no es un acto individual bancario de depósito de bienes en otros, ni una conmiseración o un apoyo moral a otro, sino que acciones que permiten promover y obtener situaciones nuevas y distintas a las que hacen el punto de partida del acto. Como lo demostró la historia del mutualismo y el sindicalismo obrero, las luchas feministas o por los derechos civiles interraciales, la verdadera solidaridad es aquella que sirve para transformar relaciones de injusticias y para crear una cultura de co-implicación.

Ésta construcción paradigmática se traduce en una disposición epistémica de integración, interculturalidad, participación y solidaridad, sino en una práctica permanente, funcional y fundante, instituyente más que constituyente, de colaboración y cooperación. Una nueva antropología no individualista supone el valor y la práctica de la cooperación como un elemento esencial.

El ser humano puede asumir distintos comportamientos: tiene la posibilidad de enriquecer o de destruir, no sólo a si mismo sino también al ambiente en el que se encuentra; puede ser agresivo o no; puede ser competitivo o solidario, sin dejar de ser competente. El comportamiento es producto de los valores que socialmente recibimos desde los inicios de la vida, de los modelos que vemos y de los refuerzos o estímulos que recibimos por hacer o no ciertas cosas, somos producto de un proceso de socialización en el cual se nos enseña a valorar comportamientos constructivos o destructivos. ${ }^{42}$

Se trata de hacer socialización no acumulativa, no competitiva ni individualista sino cooperante.

Participación, solidaridad, colaboración, en su sentido sustantivo, significan además dos cosas que alteran la forma de organización jurídica y económica con que se han moldeado hasta ahora nuestras sociedades modernas. Por un lado concebir lo político y el poder de una manera distinta a la centralización y formalidad del control de las sociedades estatales modernas; por otro despensar el orden como cerrado y bajo control y revalorizar el caos y el conflicto.

No basta solo con discutir acerca del papel del estado frente a las políticas públicas, sus posibilidades de acción frente a los flujos globales políticos y económicos globales o la forma de organización territorial y administrativa del Estado, sino antes que esa discusión pensar organizaciones y acciones políticas en un nuevo patrón sociocultural que opten por la descentralización hacia los espacios locales, construir entornos próximos, abandonar la lógica centro/periferia para hacer experiencias locales con proyección. Desde el Estado y las políticas públicas implica transferir real y efectivamente poder hacia los ciudadanos, cambiando la

42 PÉREZ OLIVERA, Enrique. Juegos cooperativos: juegos para el encuentro. Disponível em: http://www.efdeportes.com/efd9/jue9.htm 
perspectiva del control por la de la producción de canales para los flujos de participación y decisión, situándose a medio camino entre el estado y la comunidad en alianza con ésta.

Desde los sujetos y las comunidades implica repensar el conflicto por las necesidades en un sentido más allá de lo reivindicativo. Todo conflicto tiene causas, por lo que cabe más que nunca aquello de hacer visible lo real para involucrarse en las causas de los conflictos, atender a ellas y remover efectivamente los obstáculos que obstaculizan la satisfacción de necesidades, aún cuando ello prive o disminuya la ganancia monetaria. En ese contexto una visión no individualista ni economicista se plantea no solo recuperar las relaciones sociales sino reponerlas en un sentido productivo; pensar una sociedad humanizada implica "sustituir el principio del lucro por el del placer y la meta del dominio por el de la creación”43.

Pensar otro paradigma social implica no solo invertir cargas tributarias o de propiedad, sino invertir el sentido de la discusión sobre necesidades y economía, colocando el acento en los satisfactores y su articulación para recrear alternativas y no en los bienes, pasando de la idea de una economía de la escasez a una de la sinergia. Pensar de otro modo implica no solo imaginar o inventar nuevas alternativas técnicas para la redistribución de los bienes sino el cómo desplazar la lógica de control de la naturaleza y de los otros para hacer economía y sociedad. Hay que desoccidentalizar también la lucha y concreción de las necesidades. Implica no solo un uso de los conocimientos y la experiencia puesta a disposición de las comunidades y los seres humanos concretos en su lucha de dignidad y satisfacción de necesidades, sino abrir un nuevo imaginario. A diferencia del paradigma occidental moderno de apropiación y disposición se trata de crear con responsabilidad alternativas de solución política.

Es en ese movimiento creativo donde radica la condición de posibilidad de un sujeto inmanente que no quede subsumido en un tipo de relaciones predefinidas y formateadas sino que sea capaz de constituirse en su potencia y en la gestión de sí y de su contexto. De hecho:

El sujeto se define por un movimiento y como un movimiento, movimiento de desarrollarse a sí mismo. Lo que se desarrolla es sujeto solo en esa acción creadora puede romperse el límite del paradigma moderno, pensar, pensarse y ser pensado de otro modo. " Solo Podemos aniquilar siendo creadores; Pero no olvidemos tampoco esto: que basta crear nuevos nombres, nuevas valoraciones y verosimilitudes para crear, a la larga, "cosas" nuevas". ${ }^{44}$

\footnotetext{
${ }^{43}$ CAPPELLETTI, Angel. La Ideología Anarquista. Santiago: Ediciones Espíritu Libertario, 2004, p. 94.

${ }^{44}$ DELEUZE, Guilles. Lógica del sentido. Barcelona: Paldos, 2005, p. 113.
} 


\subsection{Cambiar la emocionalidad}

Sin embargo hacer visible, mirar y pensar de otro modo resultarán ejercicios carentes de sentido si se reduce ese movimiento solo a un acto de razón, a una enunciación de laboratorio, de reflexión no de práctica de relacionamento. A su vez, resulta insuficiente un compromiso de "buenos sentimientos" por las causas nobles o una "ira justificada" en contra de los abusos del sistema global. Las posiciones que se encuentran en una u otra condición, incluso en una combinación de ambas sin integrarlas en un nuevo sentido adolecen del mismo defecto: se ubican dentro del paradigma moderno de la separación, de la escisión mente/cuerpo, razón/sentimientos. De lo que se trata en definitiva no es de sustituir un pensamiento por otro, una adecuación a nuevas normas, sino cambiar la emocionalidad para modificar la conducta en una nueva ontogenia creativa en el entorno bio-social.

Existe una diferencia sustancial entre el comportamiento como parte de un orden dado y una conducta creadora de un orden distinto. Una conducta es más que un comportamiento. "Se llama conducta a los cambios de postura o posición de un ser vivo, que un observador describe como movimientos o acciones en relación con un ambiente determinado" y que a diferencia de meras repeticiones, es precisamente el acto de adecuación/creación lo que genera fenómenos sociales. Al "entender como fenómenos sociales a los fenómenos asociados a la participación de los organismos en la constitución de unidades de tercer orden" podemos observar que precisamente el carácter de lo humano radica en realizar esos acoplamientos estructurales produciendo ontogenia creativa y no repetición subordinada por hábito al orden normativo impuesto.

Un emocionar creativo significa implicación y relación adaptativo/creativa, diferenciado de mecanismos triviales de segundo orden, recuperando lo humano, humanizando la vida no en un sentido moderno sino en un sentido radical en tanto proceso cultural que abre los bloqueos dominantes de la modernidad capitalista y mecanicista hoy global, provocando una "tendencia hacia la ampliación constante de lo humano más allá de los límites en los que los procesos ideológicos pretenden encerrarnos" 45 , se requiere una disposición anímico-volitiva esencialmente práctica para el ejercicio de procesos neoparadigmáticos, no solo deducirlos y pensarlos. Sin un involucramiento más allá de discursos y prácticas "consecuentes" con ese razonamiento de inicio, sin producir sentidos no lineales de coherencia, permaneceremos presos

\footnotetext{
${ }^{45}$ HERRERA FLORES, Joaquin. Hacia una visión compleja de los Derechos Humanos. En El vuelo de Anteo. Derechos Humanos y Crítica de la razón liberal. Editorial desclée de Brouwer, S.A. Bilbao, 2000, p. 205.
} 
dentro de la lógica lineal que disocia público de privado, personal de colectivo, pero nunca reintegra ni religa las esferas de existencia del humano.

Se trata de cambiar la realidad no desde la enunciación de promesas o de normas programáticas, sino de cambiar la acción para esa construcción, lo que supone una (otra) concepción del conflicto orientado a la experiencia, al aprendizaje a una nueva acción/gestión de la razón y la emoción puestas en el hacer. Los conflictos humanos jamás se resuelven desde la razón sino de una articulación consciente y creativa de posición y disposición; sin ello no se transforma la cotidianeidad.

\subsection{Modificar las Interacciones}

Una nueva acción social desde una antropología no individualista ni sexista, que se proponga superar el mito del bien común por simple agregación de individualidades, debe construirse sobre intercambios diferentes, no solo nominalmente colectivas o comunitarias sino sinérgicamente inter-relacionantes e inter-actuantes. $Y$ estas interacciones no se improvisan.

Atrapados en la tensión inmovilizante que divide el accionar entre lo público y lo privado, política profesional y polis, con una economía desvinculada de las necesidades humanas y su satisfacción fuera de las redes del mercado, resulta indispensable plantearse la necesidad de construir mecanismos, prácticas, metodologías de integración, intercambio y sinergia que produzcan, reproduzcan, refuercen y/o reactiven el principio de comunidad.

En el proceso histórico de construcción de los estado-nación las esferas del estado y del mercado se apropiaron de la soberanía, establecieron mecanismos decisorios mediatizados o encarnados en el etéreo "mercado" como mascara de los dueños del capital, y a partir de un sistema político que genera expectativas en base a promesas en que corresponde al Estado el mecanismo de solución y contención de las poblaciones sin tocar al mercado, al que adicionalmente en las últimas décadas se le ha entregado cada vez más espacios antes públicos

Por éstas razones el sistema político no solo está sobrecargado de problemas para los que ya no tiene la competencia y la información necesarios para solucionarlos, sino que llega a encontrarse en una auténtica situación de bloqueo, puesto que los instrumentos tradicionales de control del ambiente, se decir, el derecho y el dinero, se vuelven insuficientes para la sociedad, que ya no los asume como instrumentos eficaces de compensación y comunicación. ${ }^{46}$

\footnotetext{
${ }^{46}$ BARCELLONA, Pietro. El individualismo propietario. Madrid: Editorial Trotta S.A, 1996, p. 104.
} 
Población no es lo mismo que comunidad, se hacen de manera diferente. "El espacio de la comunidad está constituido por las relaciones sociales desarrolladas en torno a la producción y reproducción de territorios físicos y simbólicos y de identidades e identificaciones con respecto a orígenes y destinos comunes y es allí donde se requiere desplegar esfuerzos de construcción de formas relacionales diferentes a las del contrato, del consumo, de la representación política, de la cooptación de las organizaciones sociales.

Cambiar la interacción requiere estadios continuos sucesivos y abiertos en una línea de tiempo no de progreso lineal. El discurso del monismo acentuado por los postmodernos conservadores de fin de la historia y otros relatos ocultan por falseamiento el horror de la repetición de la fórmula moderna de interacción estado-mercado como alianza única, señalando que todo caos es terror y oscureciendo que es el cambio y la deriva lo que genera subsistencia vital y no la iteración de respuesta.

La interacción en el espacio comunidad es un camino coherente con la superación de la crisis del paradigma moderno. Es una regla de la biodiversidad que entre los organismos los encuentros generan cambios de relación individuo-medio y reorganización ontogénica no solo de adaptación sino de reorganización estructural no siempre modelada. La bio-socio-diversidad debe tenerse en cuenta. Generar nuevas realidades levantando no sólo discursos de cambio sino prácticas y metodologías para ese encuentro y la interacción creativa es urgente, produciendo una convergencia de las prácticas liberadoras como momentos constituyentes, buscando en ellas la realización de un modelo de democracia, y por tanto de ciudadanía, de educación y formación permanente, que reconozca el papel constituyente de la división y el conflicto. Plantearse la afección entre los sujetos, los compromisos de relacionamiento a pesar de las diferencias, la expresión de divergencias en un sentido no solo de ruptura sino de fluidez. A esa producción de metodología hay que abocarse, despensando y repensando las juridicidades y economías de lo social. Se trata de un horizonte de dignidad material cultural y de sustentabilidad de la vida y su riqueza frente a los sistemas que pretenden reducir a los sujetos a una interfase del entorno de las comunicaciones del poder y las finanzas.

\section{CONCLUSIÓN}

La reflexión que desarrollamos ha intentado por un lado alejarnos de tres nudos que impiden estados de emancipación: uno, romper con la idea moderna que existe una epistemología y una ciencia única capaz de producir leyes para todo fenómeno; dos, que el 
estado de cosas que se dicen desde ese paradigma son verdades naturales, únicas y absolutas; tres que frente a la idea de una teoría total que se constituye en pensamiento único no es necesario oponer otra teoría total sino construir alternativas a partir de una metodología del movimiento y la interacción. Por el otro, señalar que esta metodología debía ser construida no solo desde reflexiones teóricas sino en articulación práctica de apertura de procesos que describimos en los cinco pasos de hacer visible lo real, cambiar la mirada, pensar de otro modo, cambiar la emocionalidad y cambiar la interacción. Sin embargo es necesario decir aún algunas cosas.

Una metodología emancipadora no es un método ni un modo en tanto modelo sino una producción de estrategias abiertas y en conexión de experiencia y saber. En tanto que el método es un conjunto de pasos establecidos en un mismo orden, en una secuencia que transforma esa ritualidad en un resultado en términos de idealidad y objetividad, una metodología es un proceso abierto, articulable, inflexivo y recursivo, capaz de reorganizarse en busca de su potencialidad, adecuándose al contexto y al grupo que participa en la generación de su comprensión, aprendizaje y construcción. De esta forma una metodología de apertura no repite sus pasos mecánicamente sino que juega probando su eficacia. Se instala precisamente en el espacio del juego en cuento entiende que es en su movimiento donde radica su propia clave, toda vez que "el juego es la búsqueda del método, la construcción grupal o individual de una forma posible de llegar a lo que se busca", lo que incluso para el investigador individual es esencial recordar, ya que en el juego nunca se está sólo ni fuera.

Una metodología del movimiento es un proceso de apertura, se propone respuestas transitorias y generar mecanismos de revisión y reposición de escenarios. Por eso es especialmente importante una metodología de éste tipo para aquellas investigaciones, acciones y trabajos de generación, defensa o constitución de derechos. En la satisfacción social no hay cosa juzgada sino marcos de estabilización transitorias. No hay lo definitivo ni una ley de verdad o norma que pueda cerrar definitivamente un estado social como un consolidado, hay estados plurales a producir. Contra el cierre de los procesos las metodologías de apertura proponen una nueva lógica: “A una lógica del orden, oponen una lógica de lo contradictorio y la incertidumbre".

Para éste tipo de metodologías el aprendizaje es fundamental, es parte del mismo procedimiento, es su potencial y su riqueza. Para el investigador su participación es, a la vez que de analista, la de un mediador, un interventor comprometido parte del proceso y que se involucra en él, saca lecciones de su experiencia, las acumula, reordena, trabaja no por 
imposición sino por memoria activa, homologando en un proceso de prueba constante su validación posible en la actualidad de los conocimientos pasados. Cuando incorporamos la necesidad de no partir de supuestos abstractos ni dar por sentadas verdades sino que hacer visible lo real, ello está basado en un largo trabajo de campo con actores sociales en busca de develar su verdadero contexto.

Así por ejemplo trabajando con jóvenes en busca de cual situación material podía servir de base para reconocer su necesidad más demandada el trabajo nos develó que reclamaban de los adultos sobre todo intimidad: viviendo en espacios hacinados su reclamo no era de carácter sexual sino de autonomía y comunicación, lo que los obligaba a salir a la calle. Aplicando matrices de necesidades a universitarios la autoestima era su necesidad vital más significante. Trabajando con mujeres que sufrían de violencia descubrimos que resultó fundamental mostrarles como el suyo era un problema colectivo y no individual. En educación a líderes sindicales descubrir las diferencias y semejanzas entre los diferentes tipos de trabajos permitió por un lado obtener una mejor definición de las necesidades de información de las diferentes áreas de trabajo (retail, trabajadores independientes, servicios públicos, educación, manufacturas) y por otra hacer que descubriesen entre ellos que debían buscar formas diferentes de interactuar que pensar eran todos lo mismo, lo que a su vez chocaba nuevamente con su ritualidad en comprender el trabajo como si existiese una sola manera de ejecutarlo; en apoyo a sindicatos para desarrollar estrategias de defensa de derechos cruzar la línea de producción con la estructura de jerarquías permitió saber donde se producían los principales conflictos y a que lógica de administración y dirección respondían.

De la acumulación, organización y reorganización de esas experiencias se fue construyendo la idea de que era imprescindible mostrar y compartir esa base de realidad común y que el proceso de encuentro y emocionalidad de los sujetos era esencial para producir interacciones nuevas. No basta llamarse compañeros para serlo.

En estos procesos de interacción la educación en su sentido no bancario resulta fundamental para que la mirada de los afectados no se cierre sino se abra a su contexto y a la experiencia de que es posible cambiar estados sociales, "porque hablar de un proceso educativos es hablar de una forma específica de adquirir conocimientos, y el crear y recrear el conocimiento, es un proceso que implica una concepción metodológica a través de la cual este proceso se desarrolla"; y esos conocimientos sistematizados y relacionados con el propio contexto producen un saber que empodera a los sujetos. Como sostenía Joaquín Herrera: 
El nivel "ejemplar" de la memoria nos permite servirnos de las injusticias sufridas en el pasado para combatirlas hoy en las formas que van adoptando en el presente. La memoria ejemplar da un nuevo sentido al combate contra las desigualdades, al insertarlo en la evolución de la explotación del ser humano por el ser humano. ${ }^{47}$

Por estas razones una metodología sistematizadora y creadora no parte de un sentido sino que lo propone y lo produce. La realidad no es algo inmóvil que debe ser adecuado a las teorías, subsumida en las definiciones normativas, sino que es a la vez punto de partida pero esencialmente punto de llegada, de creación del acto de asumir la realidad y transformarla: "el sentido no es nunca principio ni origen, es producto". Es esta idea de sentido que reemplaza a la verdad el gran salto de un saber/hacer no moderno ni liberal.

Resulta en consecuencia acertado decir que una metodología como la que proponemos es una metodología de la potencia; pone tanto como objeto de su trabajo a la vez que como objetivo de su accionar que genere sujetos dueños de sí y creadores de sus condiciones de posibilidad; la dinámica (dynamis) que se opone a lo inmutable.

Se trata finalmente de una metodología materialista y finalista. Materialista en su origen, su proceso y su punto de llegada, porque parte de la realidad material, se desarrolla en su conocimiento y en su análisis, en aprender y aprehender de ella y en volver a las relaciones e interacciones efectivas para su transformación. Y finalista por que se propone desde un inicio la satisfacción de las necesidades humanas y se orienta a ese objetivo y no a una noción de orden que desplaza esa satisfacción a una razón abstracta de tiempo y sentido.

Para aterrizar en las tareas políticas y prácticas que emanan de nuestra apuesta y que derivan de ellas, tres pistas de futuro pueden ayudarnos:

Primero, estas prácticas de pensar/hacer/saber requieren un constante sentido profanador. Como recuerda Agamben profanar significa no solo abolir las prohibiciones sino hacer de ellas un nuevo uso, jugar con ellas. "La creación de un nuevo uso, es, así, posible para el hombre solamente desactivando un viejo uso, volviéndolo inoperante"48. La acción metodológica se dirige a la tarea de recuperar continuamente el uso común de las cosas.

Segundo, contra el pensamiento des-subjetivante de la técnica, su sentido abstracto, contra el pensamiento que pretende que esa respuesta abstracta y técnica es la única respuesta posible y limita la creación a los límites del orden, el pensar/hacer/ saber requiere siempre de luchar contra la uniformidad y recuperar la pluralidad de las respuestas.

\footnotetext{
${ }^{47}$ HERRERA FLORES, Joaquin. Hacia una visión compleja de los Derechos Humanos. En El vuelo de Anteo. Derechos Humanos y Crítica de la razón liberal. Editorial desclée de Brouwer, S.A. Bilbao, 2000, p. 215. ${ }^{48}$ AGAMBEN, Giorgio. Profanaciones. Buenos Aires: Adriana Hidalgo Editoria, 2005, p. 112.
} 
Tercero, el método del ejercicio de lo común comienza en la proposición del sí individual y colectivo, articulado; en voluntad de poder aplicada, en la interacción y en el habitar del entorno, en su reapropiación y su cuidado.

Trabajar en prácticas conformadoras de ésta metodología es la tarea política por hacer. El modo del método es la acción directa.

\section{REFERENCIAS}

AGAMBEN, Giorgio. Profanaciones. Buenos Aires: Adriana Hidalgo Editoria, 2005.

APARICIO GUADAS, Pep. El camino de re/invención de la ciudadanía y la educación popular. En Polis, Revista de la Universidad Bolivariana. Volumen 1, № 2. Santiago: Universidad Bolivariana, 2001.

BALANDIER, Georges. El desorden. LA teoría del caos y las ciencias sociales. Barcelona: Gedisa Editorial, 1988.

BARCELLONA, Pietro. El individualismo propietario. Madrid: Editorial Trotta S.A, 1996.

BARCELLONA, Pietro. Postmodernidad y Comunidad. El regreso de la vinculación social. Madrid: Editorial Trotta S.A, 1992.

BATESON, Gregory. Espíritu y Naturaleza. Buenos Aires: Amorrortu Editores, 1990.

BAUDRILLARD, Jean. El Intercambio Imposible. Madrid: Ediciones Cátedra, 2000.

BERMAN, Morris. El reencantamiento del mundo. Santiago: Editorial Cuatro Vientos, 1999.

CAPPELLETTI, Angel. La Ideología Anarquista. Santiago: Ediciones Espíritu Libertario, 2004.

CENTRO DE INVESTIGACIÓN Y DESARROLLO DE LA EDUCACIÓN. Técnicas participativas para la educación popular. Santiago: CIDE Alforja, 1987.

CONDE, Fernando. Las perspectivas metodológicas cualitativa y cuantitativa en el contexto de la historia de las ciencias. In: DELGADO, Juan Manuel; GUTIÉRREZ, Juan (Orgs). Métodos y técnicas cualitativas de investigación en ciencias sociales. Madrid: Editorial Síntesis, 1995.

DELEUZE, Guilles. Empirismo y subjetividad. Barcelona: Gedisa, 2002.

DELEUZE, Guilles. Lógica del sentido. Barcelona: Paldos, 2005.

DESCARTES, René. El discurso del Método. Madrid: Ediciones Akal, S.A, 1989.

ELIZALDE, Antonio. Desarrollo Humano y Ética para la sustentabilidad. Santiago: PNUMAUniversidad Bolivariana, 2003. 
FEYERABEND, Paul. Tratado contra el método. Madrid: Editorial Tecnos, 2000.

FOERSTER, Rolf. Sociedad Mapuche y Sociedad chilena. En Polis, Revista de la Universidad Bolivariana. Volumen 1, № 2. Santiago: Universidad Bolivariana, 2001.

Foucault Michel. Tecnologías del Yo. Barcelona: Ediciones Paidos Ibérica S.A., 1995.

HERRERA FLORES, Joaquin. Hacia una visión compleja de los Derechos Humanos. En El vuelo de Anteo. Derechos Humanos y Crítica de la razón liberal. Editorial desclée de Brouwer, S.A. Bilbao, 2000.

HERRERA FLORES, Joaquin. El Proceso Cultural Materiales para la creatividad humana. Sevilla (Andalucía): Aconcagua Libros, 2005.

HUME, David. Tratado de la naturaleza humana. Tomo 1. Madrid: Calpe, 1923.

JACQUES PARRAGUÉZ, Manuel. Modelo de participación por afección: un modelo para el desarrollo de la ciudadanía local. Disponível em: www.revistapolis.cl/5/jac.htm

KELSEN, Hans. Teoría Pura del derecho. Buenos Aires. Eudeba, 1999.

LOCKE, John. Tratado sobre el Gobierno Civil. Madrid: Alianza Editorial, 1990.

MARTíNEZ MIGUÉLEZ, Miguel. Un Nuevo Paradigma Para La Ciencia Del Tercer Milenio. En Las Nuevas Utopías de la Diversidad. Lo deseable vuelve a ser posible. Santiago: Universidad Bolivariana, 2003.

MATURANA, Humberto; VARELA, Francisco. El árbol del conocimiento. Las bases biológicas del entendimiento humano. Buenos Aires: Editorial Lumen, 2003.

MORIN, Edgar. Introducción al pensamiento complejo. Séptima Edición. Barcelona: Editorial Gedisa S.A., 2004.

MORIN, Edgar. El método. La naturaleza de la naturaleza. Madrid: Cátedra, 1999.

NIETZSCHE, Friedrich. La Gaya Ciencia. Buenos Aires: Gradifco 2004.

PÉREZ OLIVERA, Enrique. Juegos cooperativos: juegos para el encuentro. Disponível em: http://www.efdeportes.com/efd9/jue9.htm

SANTOS, Boaventura. Crítica de la Razón Indolente. Contra el desperdicio de la experiencia. Bilbao. Editorial Descleé de Brouwer, S.A. 2003.

SCHEINES, Graciela. Juegos inocentes, juegos terríbles. Buenos Aires: Eudeba, 1998.

SENDÓN DE LEÓN, Victoria. ¿Que es el feminismo de la diferencia?. Disponível em: http://www.mujeresenred.net/spip.php?article1571

SENNETT, Richard. El declive del hombre público. Barcelona: Ediciones Península, 2002 
ISSN 1981-3694

(DOI): $10.5902 / 1981369430496$

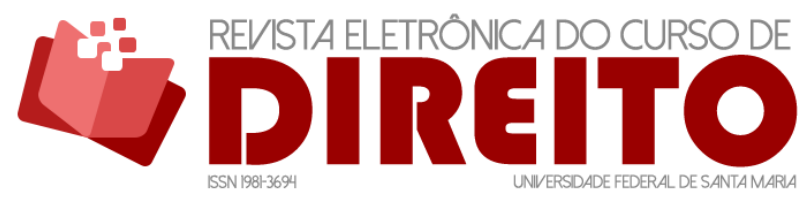

NECESIDADES, DERECHOS Y METODOLOGÍA DE APERTURA

VARGAS E. V; LATOUR B.; KARSENTI B.; YAÏT-TOUATI F. El debate entre Gabriel Tarde y Emile Durkheim. EMPIRIA. Revista de Metodología de Ciencias Sociales. N 23, enero-junio, 2012.

WALLERSTEIN, Inmanuel. Geopolítica y geocultura. Ensayos sobre el moderno sistema mundial. Barcellona: Kairos, 2007.

WITTGENSTEIN, Ludwig. Tractatus lógico-philosopicus. Madrid: Alianza Editorial, 2009.

Artigo convidado / Publicado em: 20.12.2017

\section{COMO CITAR O ARTIGO (ABNT)}

ASTETE, Rodrigo Calderón. Necesidades, derechos y metodologia de apertura. Revista Eletrônica do Curso de Direito da UFSM,

Santa Maria, RS, v. 12, n. 3, p.1101-1130, dez. 2017. ISSN 1981-3694. Disponível em:

<https://periodicos.ufsm.br/revistadireito/article/view/30496>. Acesso em: dia mês. ano.

doi: http://dx.doi.org/10.5902/1981369430496. 